\title{
Experimental Evaluation of the Energy Performance of an Air Vortex Tube when the Inlet Parameters are Varied
}

\author{
E. Torrella ${ }^{1}$, J. Patiño ${ }^{2}$, D. Sánchez ${ }^{2}$, R. Llopis ${ }^{2}$ and R. Cabello*,2 \\ ${ }^{\text {I}}$ Department of Applied Thermodynamics, Camino de Vera, 14. Polytechnic University of Valencia, E-46022 Valencia, \\ Spain \\ ${ }^{2}$ Department of Mechanical Engineering and Construction, Campus de Riu Sec. Jaume I University, E-12071 Castellón, \\ Spain
}

\begin{abstract}
The paper presents the analysis of the energy performance of an air vortex cooling tube under variations of the air inlet properties, with three independent experimental tests validated through the energy balance in the device.

The experimental analysis includes the following variations of the input conditions: First, the effect of the air inlet pressure to the vortex tube, focused on the analysis of temperature variations in the output cold stream and in the cooling capacity when the cold flow fraction varies. Second, we studied air inlet temperature variations to the vortex tube under different cold flow fractions, which is an analysis not found in the literature. And finally, is studied the performance of the vortex tube when the insulation is provided or in absence of insulation.
\end{abstract}

Keywords: Vortex tube, refrigeration system, energy analysis.

\section{INTRODUCTION}

The Vortex effect was first observed by Ranque [1] while observing thermal division in a cyclone separator, being his design improved by Hilsch [2]. Kassner and Knoernschild [3] performed a theoretical study based on the assumption that the effect was due to adiabatic expansion, which led to a low temperature in the low pressure area near the axis of the tube. Subsequently, other researchers have proposed different theories to explain the energy separation process, some of the most important referenced in chronological order are: Webster [4], Fulton [5], Sheper [6], Harnett et al. [7], Lay [8,9], Deissler et al. [10], Reynolds [11], Lewellen [12], Lindstrom [13], Kurosaka [14], Amitani et al. [15], Stephan et al. [16], Arbuzov et al. [17], Gutsol et al. [18], Lewis et al. [19], Ahlborn et al. [20], Trofimov [21] and Colgate [22]. Notwithstanding these efforts, a theory which satisfactorily explains the entire process has not been developed yet. Despite the above statement and the low energy efficiency of the vortex tube, they are commercialized for different applications when compactness, reliability and low cost are the main factors and when energy efficiency becomes less important. Currently, they are used to cool parts of machines, dehumidify gas samples, cool electrical panels, liquefy natural gas (Fin'ko [23, 24]), cool under adverse conditions (Baz et al. [25, 26]), chill laboratory environments in

*Address correspondence to this author at the Department of Mechanical Engineering and Construction, Campus de Riu Sec. Jaume I University, E12071 Castellón, Spain; Tel. +34 964 728135; Fax: +34 964 728106;

E-mail: cabello@uji.es explosive atmospheres (Bruno [27]), in hyperbaric chambers (Baz et al. [28]), separate particles (Riu et al. [29]), in nuclear magnetic resonance (NMR) (Martin et al. [30]), perform rapid PCR (Polymerase Chain Reaction) with realtime optical detection [31]. Furthermore, vortex tubes operate as suction devices (Alhborn et al. [32]) and as expanders in transcritical $\mathrm{CO}_{2}$ cycles (Sarkar et al. [33]). Recently, Sachin et al. [34] and Orhan et al. [35] studied different geometries for the cold end to improve the energy performance of the vortex tube.

In contrast to the existing experimental analysis of air vortex tubes, which mainly focuses on studying their performance under variations of the cold flow fraction with constant inlet temperature properties, the objective of this work is to analyse the incidence of the airflow input parameters (inlet pressure and inlet temperature) on its energy performance. Specifically, we analyse the outlet temperature of the cold stream, the cooling capacity provide and the COP reached by the refrigerating device. Accordingly, this work pretends to contribute to the understanding of the real performance of air vortex tubes.

\section{EXPERIMENTAL TEST BENCH AND ANALYSIS}

The experimental test bench developed for this work is shown in Fig. (1). This experimental set up incorporates an EXAIR BP3215 vortex tube (maximum volumetric flow rate $0,007078 \mathrm{~m}^{3} / \mathrm{s}$ in standard conditions at $690 \mathrm{kPa}$ of inlet pressure). The assembly is thermally isolated from the compressed air entrance in the cold and hot outlets.

We measure temperature with K-type thermocouples and pressure with piezoelectric transducers placed at the inlet and hot and cold exits. The uncertainties, calibrated using 

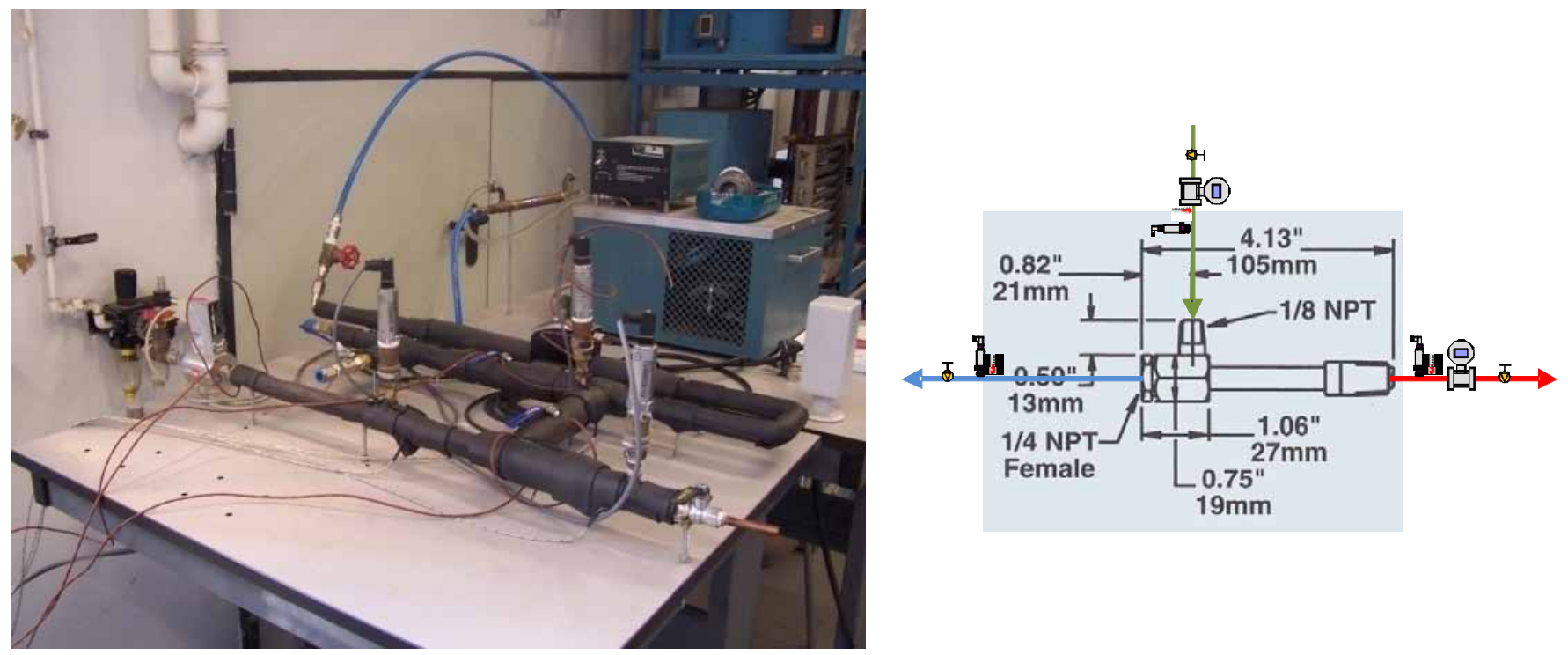

Fig. (1). Test bench and sensors location.

certified references, are of $\pm 0.5{ }^{\circ} \mathrm{C}$ for the thermocouples and of $\pm 0.1 \%$ of the full scale range $(0-1000 \mathrm{kPa})$ for the pressure transducers. We measure temperature on the outer surface of the tubes, since according to Ahlborn [36], to measure the temperature of moving fluids, a device moving at the speed of the flow should be used so as to achieve thermal equilibrium.

We use two mass flow meters, one for the inlet air (Testo 6441 , with precision $\pm 0,3 \%$ of full scale) and other for the hot exit air (Bronkhorst model EL-Flow F112AC, with precision $\pm 0.1 \%$ full scale). The signals are gathered by an AGILENT 34970A data acquisition system.

\section{VORTEX TUBE CHARACTERIZATION}

The main parameters that characterize the operation of a vortex tube are the following:

\subsection{Cold Flow Fraction}

Cold flow fraction ratio is the ratio between cold flow and inlet flow:

$r=\frac{m_{c}}{m_{\text {in }}} ; 0 \leq r \leq 1$

\subsection{COP}

As for any refrigeration plant, COP is the ratio between the cooling capacity produced and the power consumption required in the installation, as presented by equation (2).

$C O P=\frac{Q_{0}}{P_{C s}}$

where the cooling capacity is calculated in the same way as in the case of a heat exchanger, taking into account the energy absorbed to cool the cold stream (3).

$Q_{0}=m_{c} \cdot c_{p} \cdot\left(T_{i n}-T_{c}\right)$

Supply of compressed air, in the case of vortex tubes, is usually provided by an independent air compressor, making it difficult to estimate the power consumption to compute the COP if a wattmeter is not available or if the air compressed is not used exclusively in the vortex facility.

According to Boswell [37], the power required to compress air from atmospheric conditions, assuming an isentropic process, can be calculated according to expression (4), where the subscripts " 2 " and " 1 " indicate the compressor output and input conditions.

$P_{C s}=\frac{\gamma}{\gamma-1} \cdot m_{i n} \cdot R \cdot\left(T_{2}-T_{1}\right)$

Using the relationships inherent in an adiabatic compression process (5) and (6),

$$
\begin{aligned}
& \frac{T_{2}}{T_{1}}=\left[\frac{p_{2}}{p_{1}}\right]^{\frac{\gamma-1}{\gamma}} \\
& R \cdot \frac{\gamma}{\gamma-1}=c_{p}
\end{aligned}
$$

and considering that air is cooled until practically to an atmospheric temperature $\left(T_{1}\right)$, what means that this is the vortex inlet temperature " $\mathrm{T}_{\text {in }}$ ", the expression of power consumption can be written as detailed by expression (7).

$$
P_{C s}=m_{i n} \cdot c_{p} \cdot\left(T_{2}-T_{1}\right)
$$

Obtaining " $\mathrm{T}_{2}$ " by means of (5), the final expression for calculating the COP with experimental data, feasible measurable, is shown in equation (8)

$$
\begin{aligned}
C O P & =\frac{Q_{0}}{P_{C s}}=r \cdot \frac{\left(T_{i n}-T_{c}\right)}{\left[T_{i n} \cdot\left[\frac{p_{i n}}{p_{1}}\right]^{(\gamma-1) / \gamma}-T_{i n}\right]} \\
& =r \cdot \frac{\left(T_{i n}-T_{c}\right)}{T_{i n} \cdot\left[\left[\frac{p_{i n}}{p_{1}}\right]^{(\gamma-1) / \gamma}-1\right]}
\end{aligned}
$$




\section{EXPERIMENTAL ANALYSIS}

The works available in literature demonstrate that the main magnitudes which affect the energy performance of a vortex tube are the inlet pressure $\left(p_{i n}\right)$ and the flow ratio $(r)$. Therefore, we evaluate the energy performance of the vortex tube with a series of trials in which the flow ratio varies inside the operating range of the device.

\subsection{Experimental Test Range}

We consider three different experiments to evaluate the performance of the vortex tube. First, it was put through three different inlet pressure levels, conditions are detailed in Table 1. Second, the influence of the inlet air temperature was evaluated, varied using a thermostatic water bath (as shown in Fig. 1) by using a small heat exchanger placed in the input current. The evaluation range of the vortex tube in this test is shown in Table 2. Finally, the effect of the thermal insulation of the vortex tube was evaluated for constant air inlet conditions, as detailed in Table $\mathbf{3}$.

\subsection{Validation of Experimental Measurements}

First, to check the validity of the experimental results we analyse the energy balance on the vortex tube, it expressed by relation (9). In the energy balance the heat transfer to the environment is neglected and potential energies are considered equal for the input and output currents (true in the experimental plant).

$P_{\text {in }}=m_{\text {in }} \cdot\left(h_{\text {in }}+E_{c, i n}\right)=m_{c} \cdot\left(h_{c}+E_{c, c}\right)+m_{f} \cdot\left(h_{f}+E_{c, f}\right)=P_{\text {out }}$

As it is illustrated by Fig. (2), the experimental tests corroborate the energy balance of equation (9). As can be observed in Fig. (2), overall energy balance shows a deviation of $\pm 5 \%$ between the total power of the device input and output. The three cloud of points correspond to the three inlet pressure levels (Table 1). The thermodynamic properties of the air were evaluated using Refprop routines [38] neglecting the moisture of the inlet air, since it presented a low moisture ratio.

\subsection{Inlet Pressure Variation Test}

First, we present the analysis of the experimental performance of the vortex tube for the inlet pressure variation test (Table $\mathbf{1}$ ).

In Fig. (3), the measured air outlet temperatures of the vortex tube are depicted. The experimental evolutions are consistent with previous experimental studies, such as those of Promvonge [39] and Saidi [40]. As it can be observed in the evolution of the outlet cold flow in Fig. (3), a minimum in temperature exists in each test. This minimum in temperature is translated to two coincident minimums in the power of the cold flow at the vortex outlet, presented in Fig. (4). In Fig. (4), we present the total power and the contribution due to the product of the mass flow by its specific enthalpy. The difference between them is the product of the mass flow by the kinetic energy.

In Fig. (5), we depict the values of cold mass flow and it specific enthalpy for the steady-state corresponding to the highest pressure in the test. It can be deduced from Fig. (5) that the cause of the minimum in the outlet temperature of the cold air and in the output powers is the outlet mass flow evolution of the cold flow.

Table 1. Inlet Pressure Variation Test Range

\begin{tabular}{|c|c|c|c|c|c|c|c|c|}
\hline Test & $\begin{array}{c}\text { Average } \mathbf{p}_{\text {in }} \\
{[\mathbf{k P a}]}\end{array}$ & $\begin{array}{c}\text { Variation } \mathbf{p}_{\text {in }} \\
{[\%]}\end{array}$ & $\begin{array}{c}\text { Average } \mathbf{V}_{\text {in }} \\
{\left[\mathbf{m}^{\mathbf{3}} \mathbf{h}\right]}\end{array}$ & $\begin{array}{c}\text { Variation } \mathbf{V}_{\text {in }} \\
{[\%]}\end{array}$ & $\begin{array}{c}\text { Average } \mathbf{T}_{\text {in }} \\
{\left[{ }^{\mathbf{0}} \mathbf{C}\right]}\end{array}$ & $\begin{array}{c}\text { Variation. } \mathbf{T}_{\text {in }} \\
{[\%]}\end{array}$ & $\begin{array}{c}\text { Average } \mathbf{m}_{\text {in }} \\
{[\mathbf{k g} / \mathbf{h}]}\end{array}$ & $\begin{array}{c}\text { Variation. } \mathbf{m}_{\text {in }} \\
{[\%]}\end{array}$ \\
\hline \hline HP & 563.35 & $-0.27 \div 0.22$ & 16.35 & $-5.13 \div 3.31$ & 20.08 & $-2.48 \div 3.00$ & 109.45 & $-4.96 \div 3.23$ \\
\hline MP & 409.22 & $-0.76 \div 0.76$ & 11.33 & $-2.97 \div 3.41$ & 21.08 & $-2.60 \div 1.20$ & 54.91 & $-2.48 \div 3.68$ \\
\hline LP & 256.86 & $-0.74 \div 0.88$ & 6.19 & $-4.77 \div 3.35$ & 21.61 & $-0.65 \div 0.84$ & 18.79 & $-4.24 \div 2.77$ \\
\hline
\end{tabular}

Table 2. Inlet Temperature Variation Test Range

\begin{tabular}{|c|c|c|c|c|c|c|c|c|}
\hline Test & $\begin{array}{c}\text { Average } \mathbf{p}_{\text {in }} \\
{[\mathbf{k P a}]}\end{array}$ & $\begin{array}{c}\text { Variation } \mathbf{p}_{\text {in }} \\
{[\mathbf{\%}]}\end{array}$ & $\begin{array}{c}\text { Average } \mathbf{V}_{\text {in }} \\
{\left[\mathbf{m}^{\mathbf{3}} \mathbf{h}\right]}\end{array}$ & $\begin{array}{c}\text { Variation } \mathbf{V}_{\text {in }} \\
{[\mathbf{\%}]}\end{array}$ & $\begin{array}{c}\text { Average } \mathbf{T}_{\text {in }} \\
{\left[{ }^{\mathbf{0}} \mathbf{C}\right]}\end{array}$ & $\begin{array}{c}\text { Variation. } \mathbf{T}_{\text {in }} \\
{[\% \mathbf{c}]}\end{array}$ & $\begin{array}{c}\text { Average } \mathbf{m}_{\text {in }} \\
{[\mathbf{k g} / \mathbf{h}]}\end{array}$ & $\begin{array}{c}\text { Variation. } \mathbf{m}_{\text {in }} \\
{[\%]}\end{array}$ \\
\hline \hline HT & 572.93 & $-0.46 \div 0.28$ & 16.22 & $-5.84 \div 3.59$ & 38.98 & $-1.57 \div 1.01$ & 103.75 & $-6.05 \div 3.93$ \\
\hline MT & 549.15 & $-0.46 \div 0.57$ & 16.02 & $-6.14 \div 2.90$ & 19.33 & $-0.56 \div 0.60$ & 104.8 & $-6.00 \div 2.98$ \\
\hline LT & 550.42 & $-0.63 \div 0.73$ & 15.89 & $-6.17 \div 4.22$ & 14.37 & $-8.87 \div 2.67$ & 105.95 & $-5.21 \div 3.85$ \\
\hline
\end{tabular}

Table 3. Test Conditions with and without Insulation

\begin{tabular}{|c|c|c|c|c|c|c|c|c|}
\hline Test & $\begin{array}{l}\text { Average } p_{\text {in }} \\
\quad[\mathrm{kPa}]\end{array}$ & $\begin{array}{c}\text { Variation } \\
{[\%]}\end{array}$ & $\begin{array}{c}\text { Average } V_{\text {in }} \\
{\left[\mathrm{m}^{3} / \mathrm{h}\right]}\end{array}$ & $\begin{array}{c}\text { Variation } \mathrm{V}_{\text {in }} \\
{[\%]}\end{array}$ & $\begin{array}{c}\text { Average } \mathbf{T}_{\mathrm{in}} \\
\quad\left[{ }^{\circ} \mathbf{C}\right]\end{array}$ & $\begin{array}{c}\text { Variation. } \mathbf{T}_{\mathrm{in}} \\
{[\%]}\end{array}$ & $\begin{array}{c}\text { Average } m_{\text {in }} \\
{[\mathrm{kg} / \mathrm{h}]}\end{array}$ & $\begin{array}{c}\text { Variation. } \mathbf{m}_{\mathrm{in}} \\
{[\%]}\end{array}$ \\
\hline WITH & 575.06 & $-7.72 \div 10.4$ & 16.12 & $-5.47 \div 11.7$ & 20.98 & $-1.66 \div 1.25$ & 109.96 & $-11.48 \div 20.78$ \\
\hline WITHOUT & 577.14 & $-9.05 \div 11.07$ & 16.41 & $-10.02 \div 8.94$ & 21.56 & $-1.68 \div 1.39$ & 112.17 & $-13.50 \div 18.28$ \\
\hline
\end{tabular}




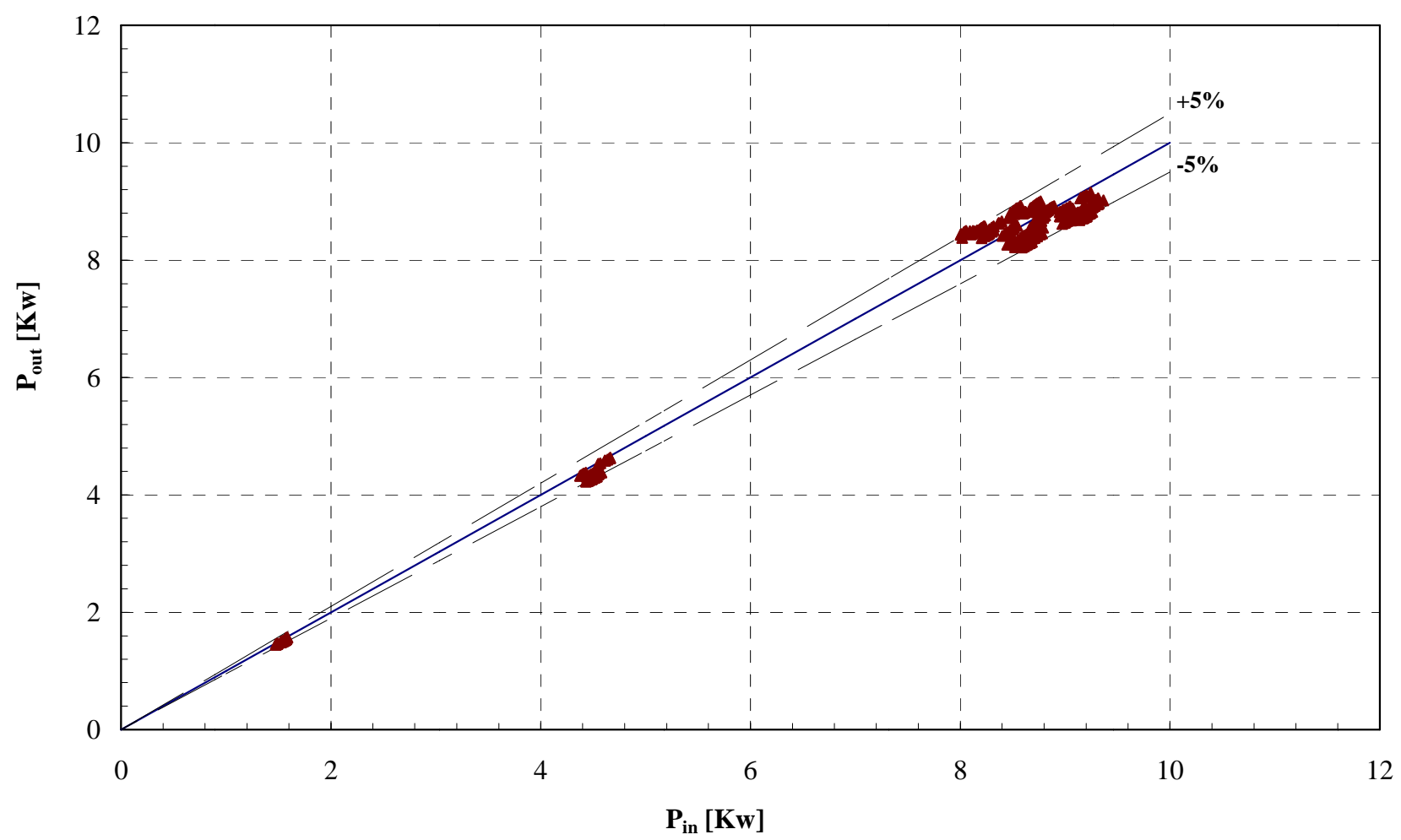

Fig. (2). Initial check. Overall energy balance in the vortex tube.

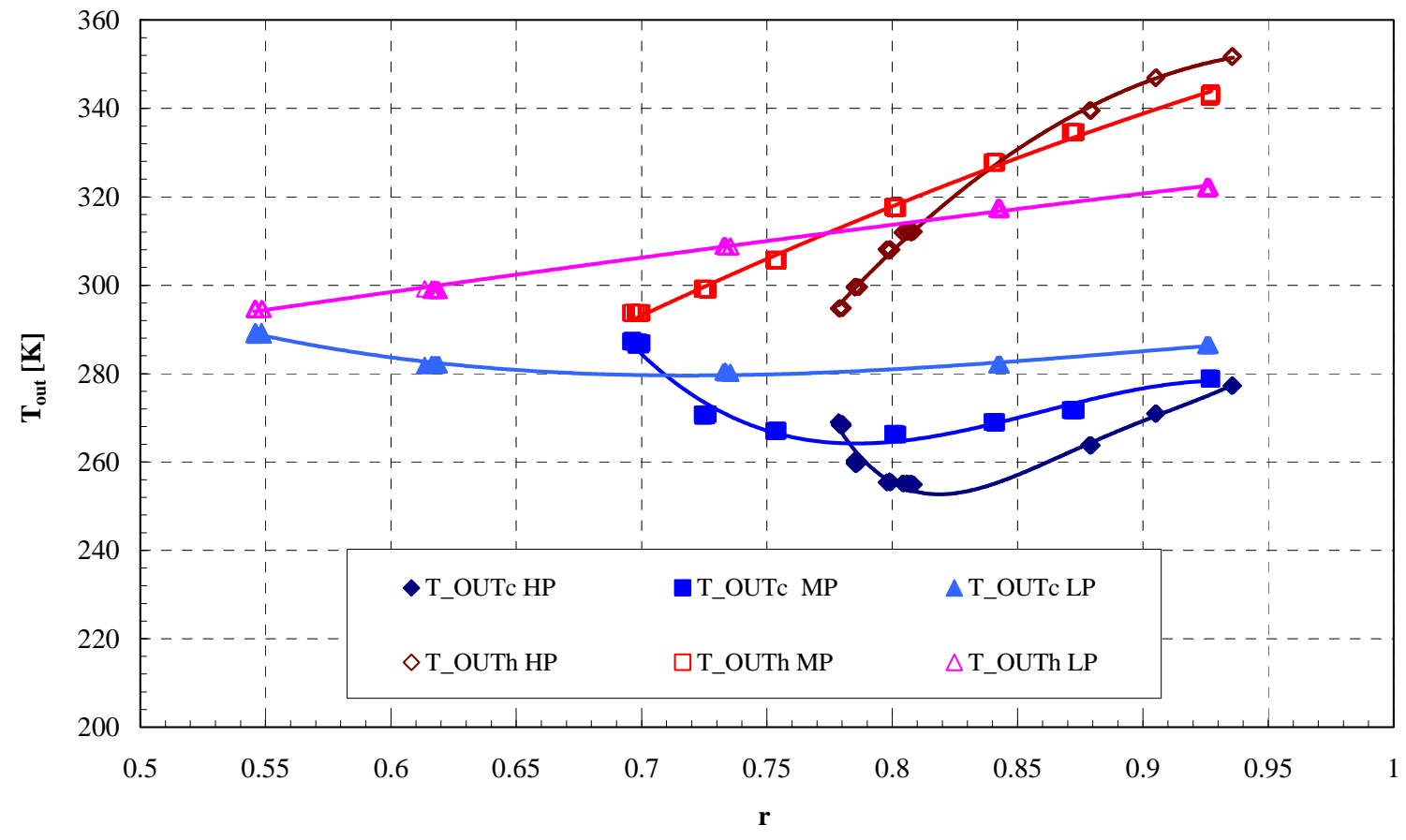

Fig. (3). Air outlet temperatures of the cold and hot streams vs flow ratio for the inlet pressure variation test.

On the other side, regarding the energy parameters, we present the cooling capacity in Fig. (6) and the COP in Fig. (7) for the three inlet pressures to the vortex tube considered. They have been represented versus the flow ratio (1).
As can be observed in Fig. (7), a maximum in COP exists for each inlet pressure level. This is because the existent relation between the cooling capacity and the temperature of the cold outlet flow (equation 3). Nonetheless, the value of the flow ratio ' $r$ ' corresponding to the minimum temperature 


\section{$\mathrm{HP}=563.35 \mathrm{kPa}$}

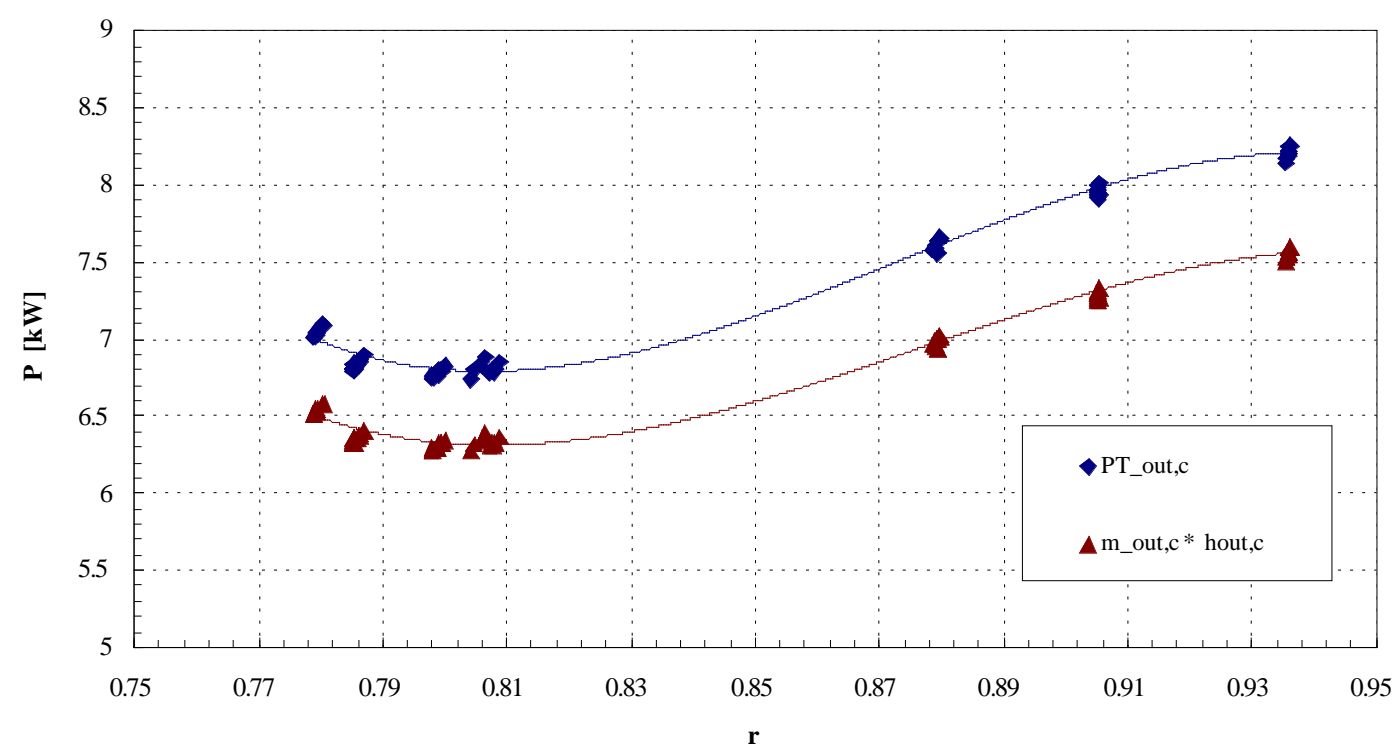

Fig. (4). Output powers for the pressure test.

\section{$\mathrm{HP}=563.35 \mathrm{kPa}$}

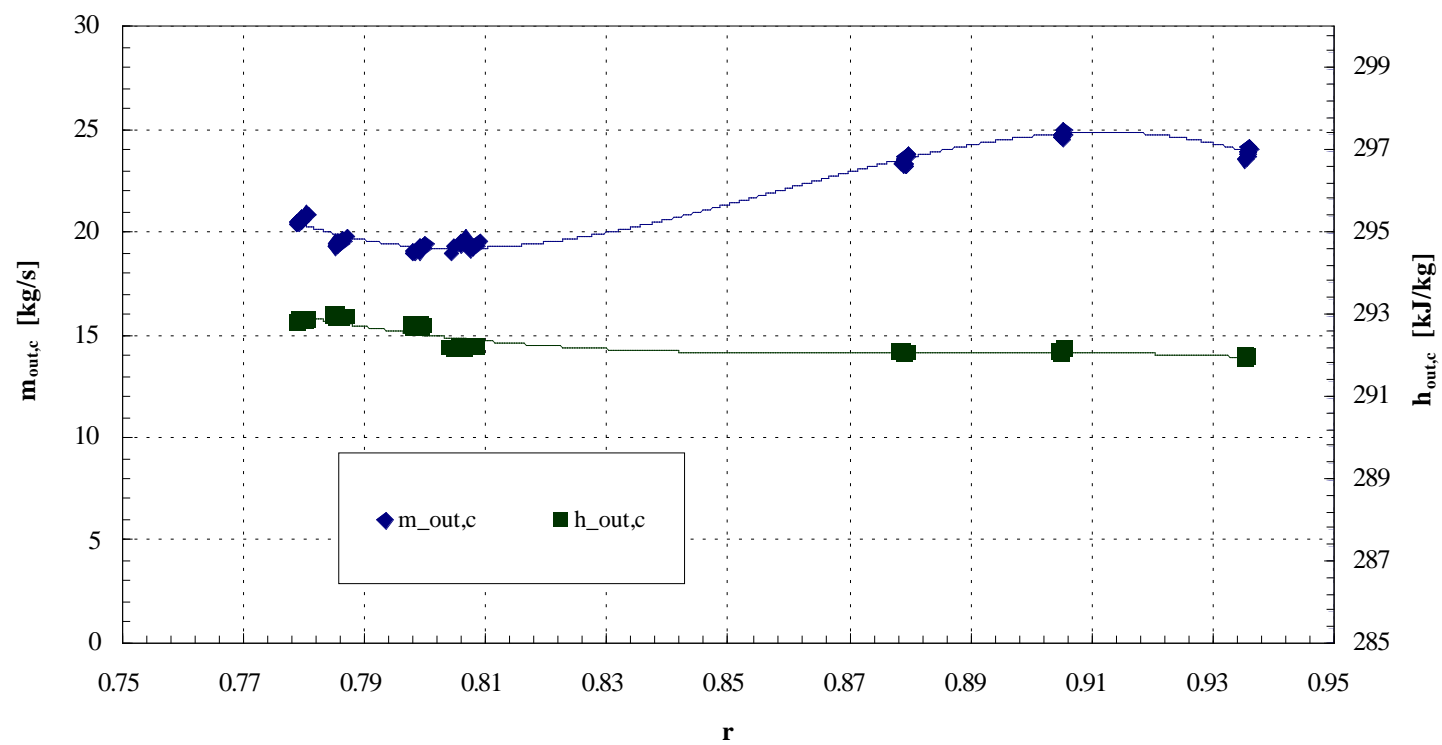

Fig. (5). Mass flow rate and specific enthalpy of the cold output current $v s$ flow ratio for the maximum pressure value.

of the outlet cold flow does not coincide with the value of the flow ratio ' $r$ ' corresponding to the maximum cooling capacity, since a variation of the mass flow exists.

Developing equation (3),

$Q_{0}=m_{c} \cdot c_{p} \cdot\left(T_{i n}-T_{c}\right)=r \cdot m_{\text {in }} \cdot c_{p} \cdot\left(T_{i n}-T_{c}\right)$

deriving (3) with respect to the flow ratio ' $r$ ',

$\frac{d Q_{0}}{d r}=m_{i n} \cdot c_{p} \cdot\left(T_{i n}-T_{c}\right)-r \cdot m_{i n} \cdot c_{p} \cdot \frac{d T_{c}}{d r}$

and equalling to zero,
$\left(T_{i n}-T_{c}\right)=r \cdot \frac{d T_{c}}{d r}$

Expression (12) establishes the value of the flow ratio ' $r$ ' which maximizes the cooling capacity. From a detailed observation of equation (12), it can be said that the value of ' $r$ ' which maximizes the cooling capacity differs from the value of ' $r$ ' which minimizes cold exit temperature, since if they were the same the value of the differential $\frac{d T c}{d r}$ would be equal to cero. Accordingly, the value of ' $r$ ' which minimizes the cold exit temperature is lower than the value 


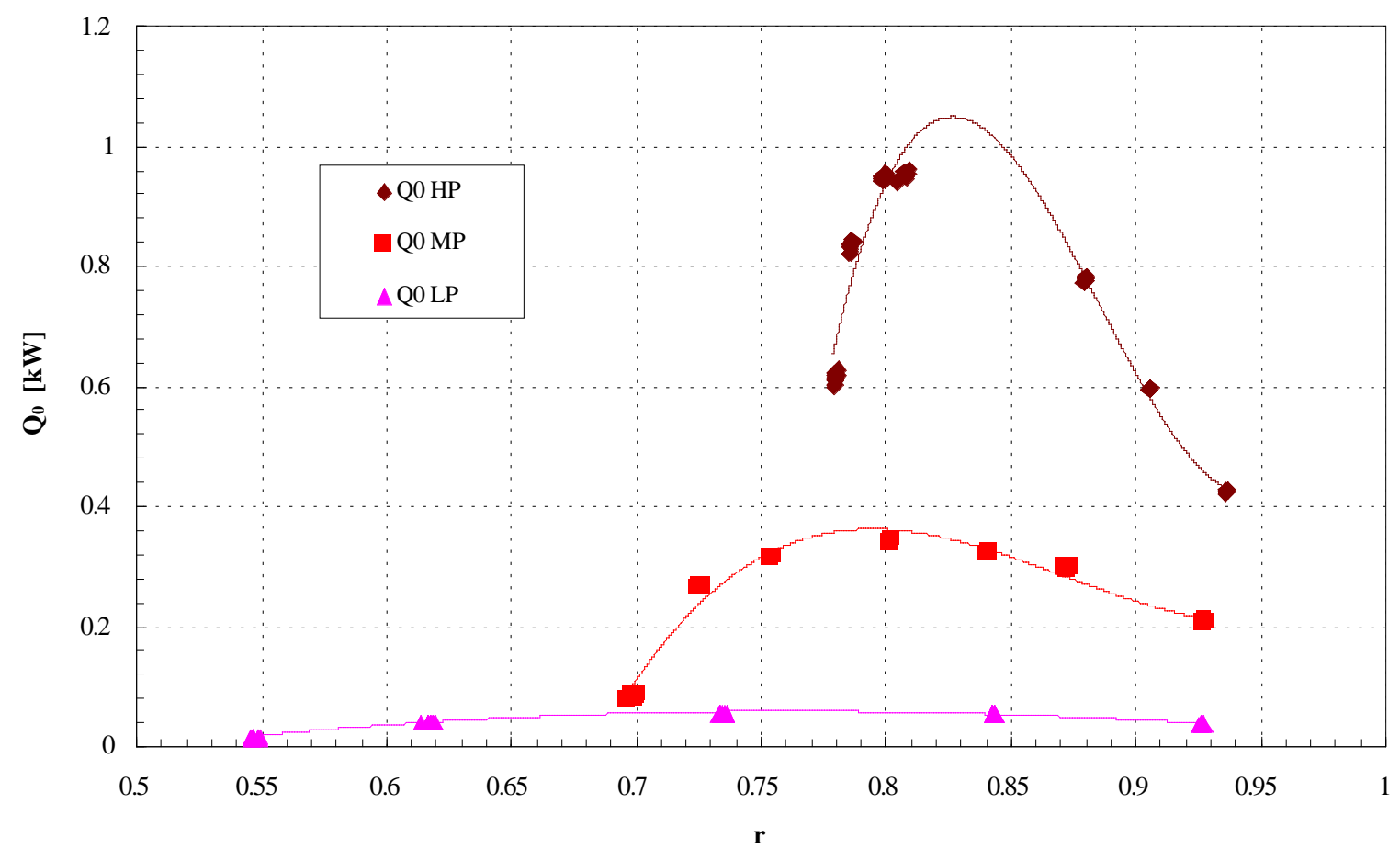

Fig. (6). Cooling capacity $v s$ flow ratio for the pressure variation test.

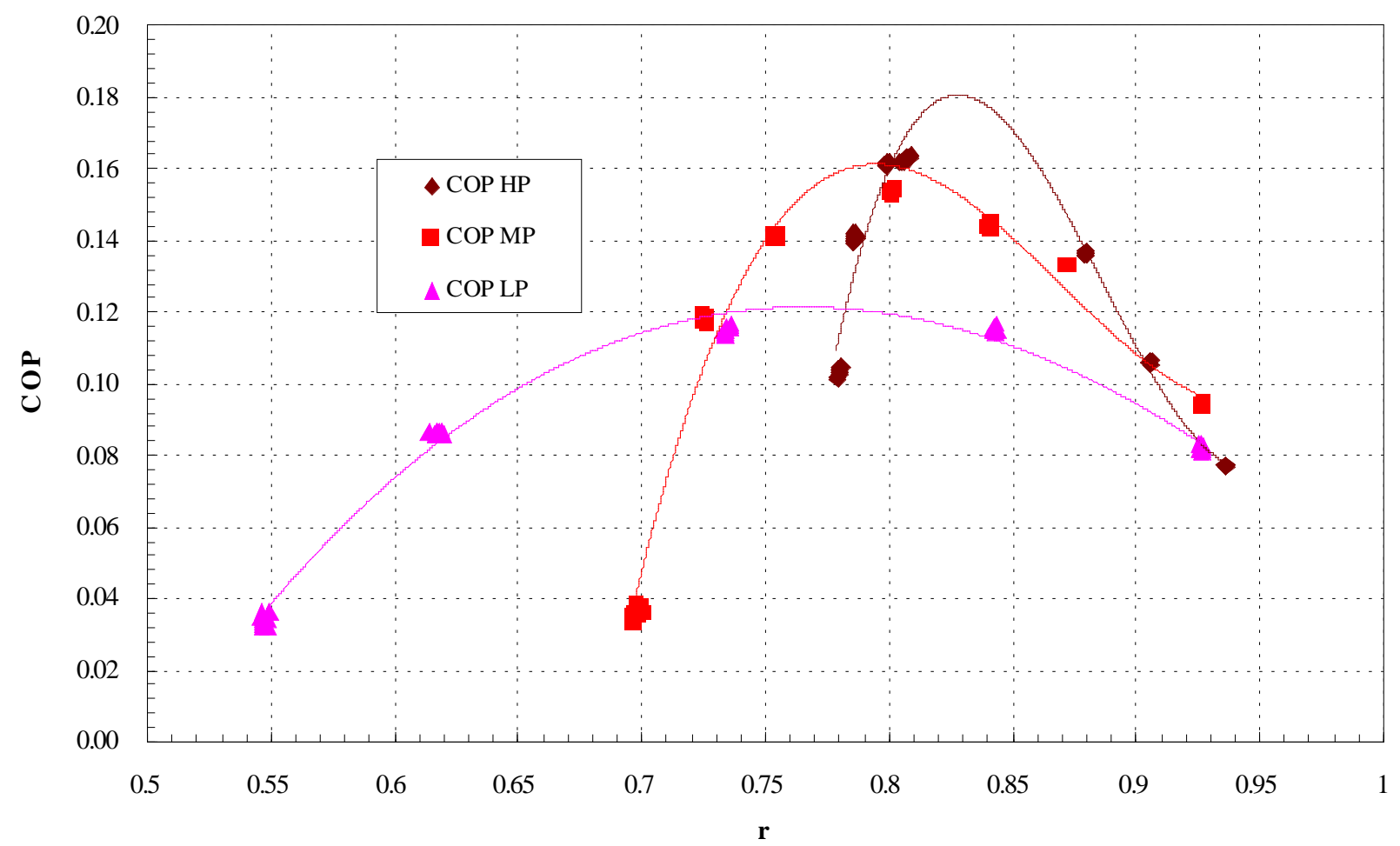

Fig. (7). COP $v s$ flow ratio for the three inlet pressures.

of ' $r$ ' which maximizes the cooling capacity. This reasoning can be observed on the representation of the cooling capacity and cold exit temperature dependence on the flow ratio ' $r$ ' on Figs. $(3,6)$ respectively.

Regarding the COP evolutions presented in Fig. (7), it needs to be mentioned that their values are higher than they would be in an actual installations, since the cooling capacity has been related with an ideal power of the compression process, which in this assay is considered to be constant for each inlet pressure.

\subsection{Inlet Temperature Variation Test}

The second experimental analysis which is performed with the vortex tube corresponds to the temperature variation of the air inlet (Table 2). This analysis has not been found in literature, accordingly this section aims to highlight the 


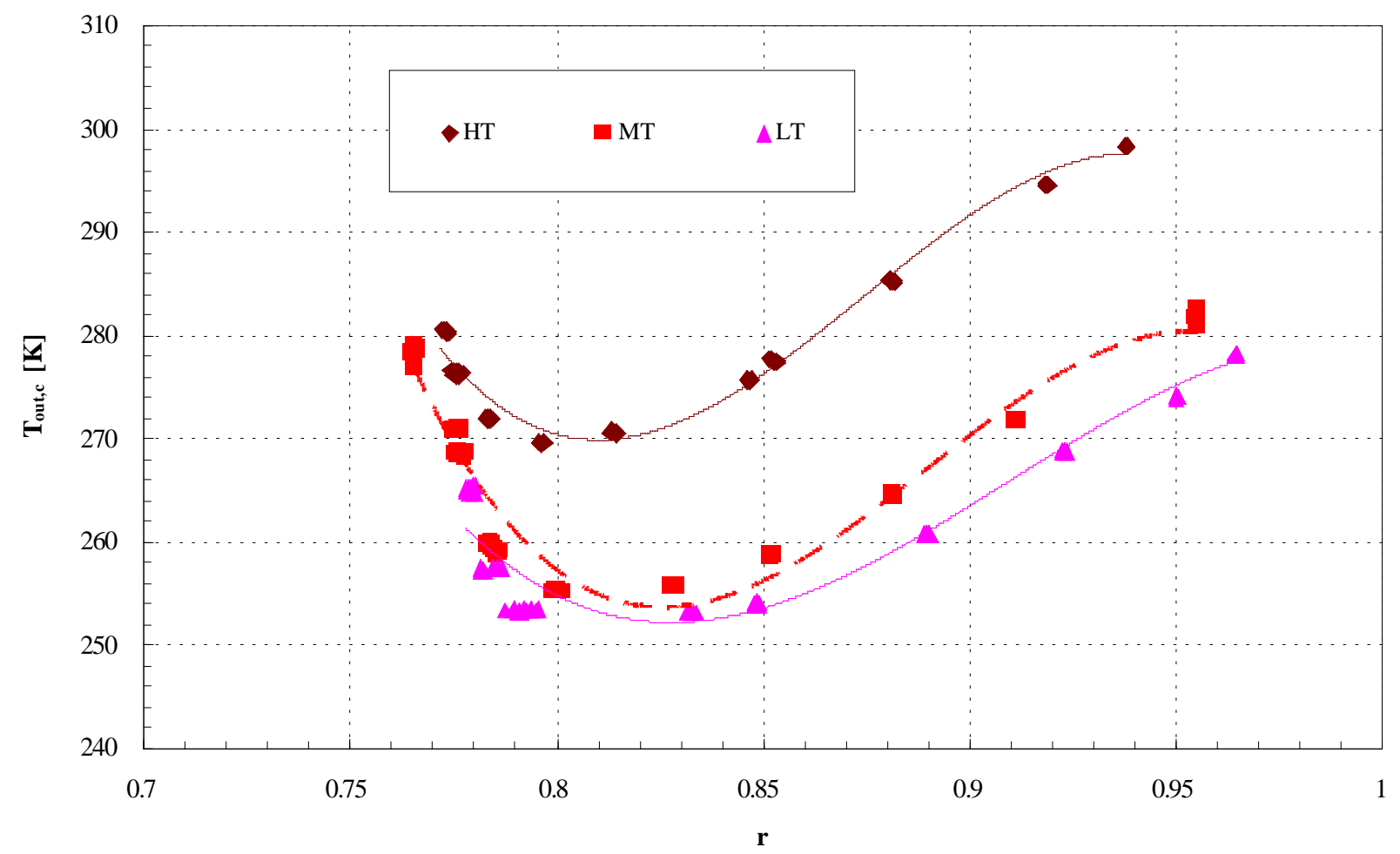

Fig. (8). Cold outlet temperature $v s$ flow ratio in the inlet temperature variation test.

impact of the air inlet temperature on the energy performance of the device.

First, in Fig. (8), we present the evolution of the cold outlet temperature for three different air inlet temperatures versus the flow ratio. It can be observed that the cold outlet temperature is as lower the air inlet temperature is. The above discussed minimum temperature for a given flow ratio exists in the experimental evolutions.

Regarding the cooling capacity, we present its evolution in Fig. (9) for the three inlet temperatures versus the flow ratio. A light increase on the cooling capacity with the increase of the air inlet temperature to the vortex tube can be

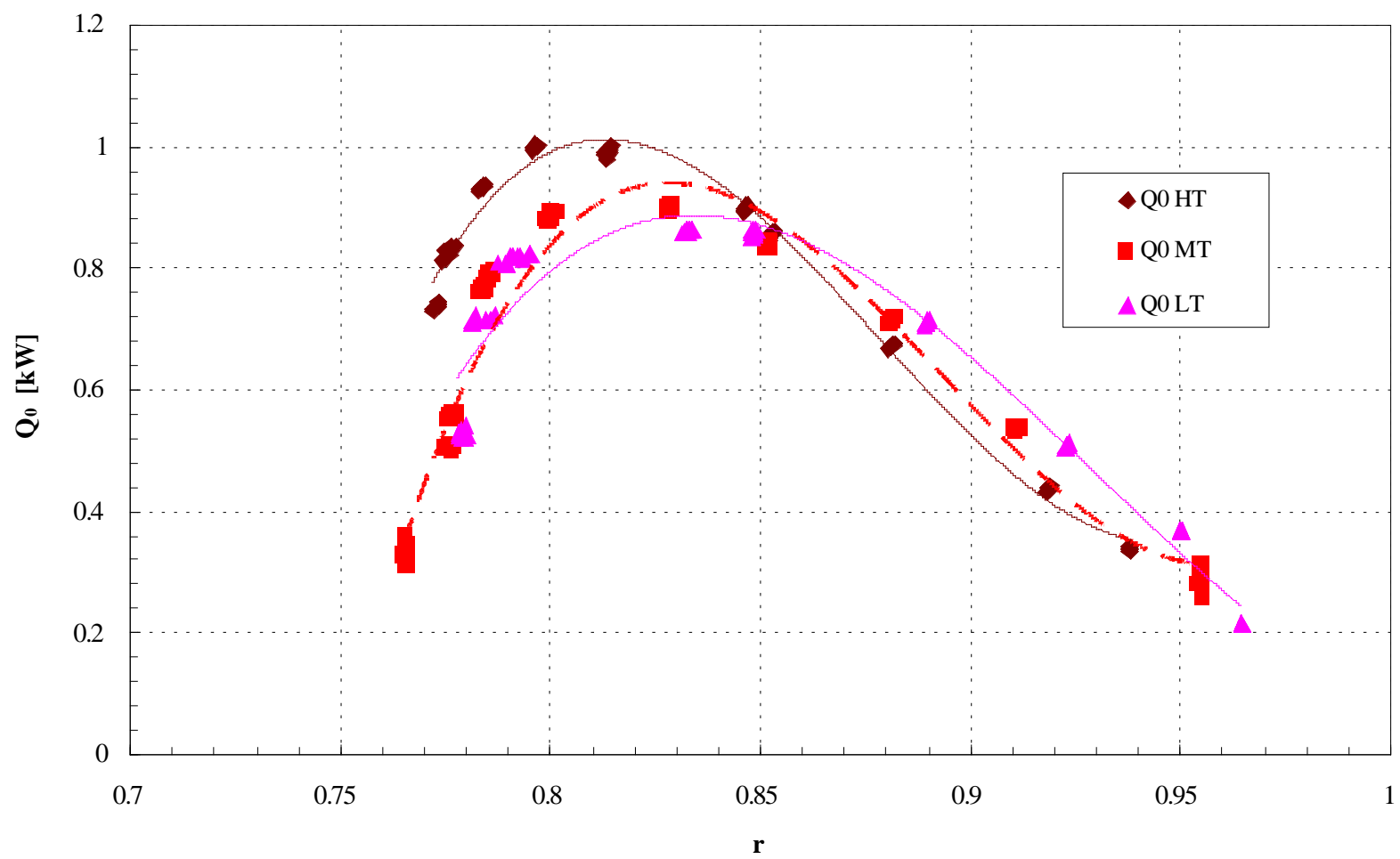

Fig. (9). Cooling capacity $v s$ flow ratio for the inlet temperature variation test. 
observed. That is because the difference between the inlet temperature and that at the cold outlet is higher when higher the air inlet temperature is.

\subsection{Insulation Test}

Finally, we analyse the effect of the insulation in the vortex tube. We evaluate this effect by comparing the energy performance of the vortex tube with insulation and with not under similar inlet conditions (Table $\mathbf{3}$ ).
We present the experimental evolution of the cooling capacity in Fig. (10) and the COP in Fig. (11).

From the analysis of the experimental evolutions, it can be affirmed that no appreciable difference exists between the results with and without insulation, and the little differences can be associated with small deviations of the test conditions.

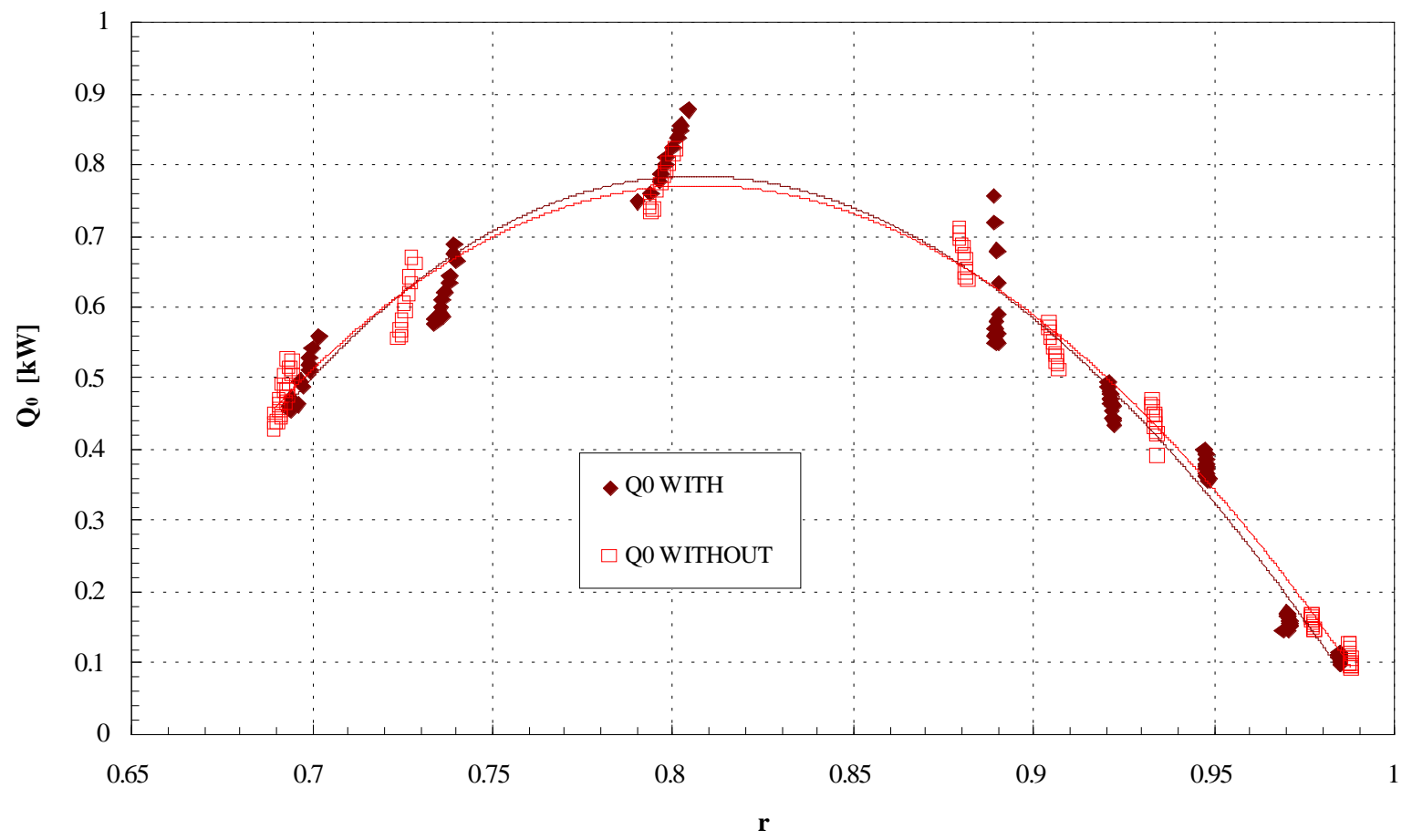

Fig. (10). Cooling capacity vs flow ratio with and without insulation.

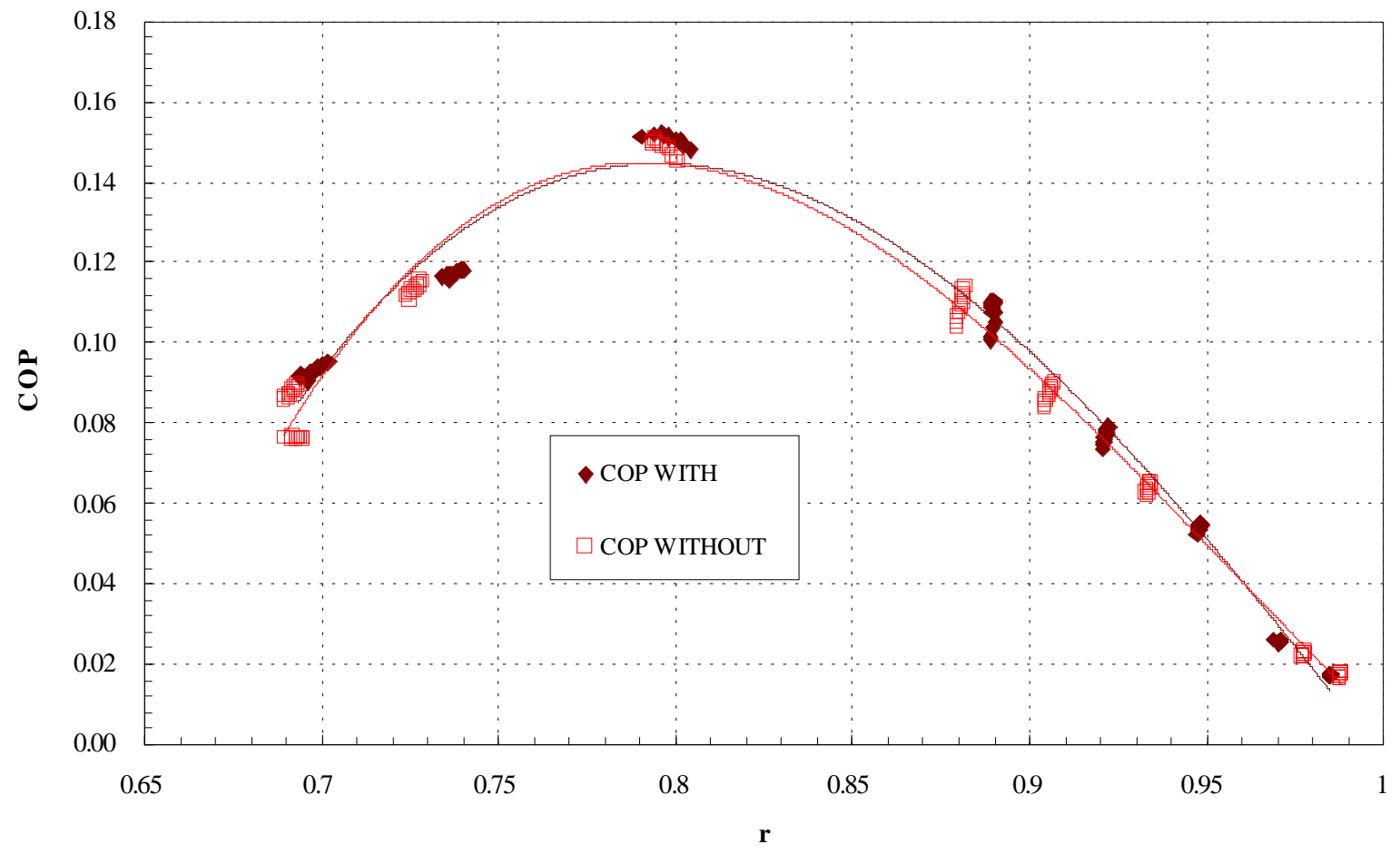

Fig. (11). COP vs flow ratio with and without insulation. 


\section{CONCLUSIONS}

We present a test bench of an air vortex tube in the present work. It allows to modify the inlet conditions of the air in order to analyze their influence in the energy performance of the device.

The paper presents the experimental evaluation of the air vortex tube under inlet pressure and temperature variations of the inlet air over a wide range of variation of the cold and hot flows, i. e., variation of the flow ratio. We validated all the experimental results with the overall energy balance in the device, obtaining an error below $5 \%$.

We observed a minimum in the output temperature of the cold flow in the inlet pressure variation test. This minimum was already evidenced in previous works, as well as its transfer to the COP values, however, this paper analyses the causes which produce this minimum. We concluded that it is associated with the variation of the mass flow rate of the cold output current. Furthermore, we analyse the values of the flow ratios at which the minimum in temperature and cooling capacity are obtained.

We studied experimentally the influence of the inlet temperature of the air to the vortex tube, and conclude that the outlet temperature of the cold flow is lower as lower the inlet temperature is. Additionally, the cooling capacity is higher when higher the inlet temperature is, since the difference in temperature between the inlet air and the cold outlet air is higher.

Finally, we evaluated the effect of the insulation of the vortex tube for constant inlet conditions, and we concluded that the insulation does not modify appreciably the energy performance of the device.

\section{NOMENCLATURE}

$$
\begin{array}{ll}
\text { COP } & =\text { Coefficient of performance } \\
c_{p} & =\text { Specific heat at constant pressure, } \mathrm{kJ} \cdot \mathrm{kg}^{-1} \cdot \mathrm{K}^{-1} \\
E_{c} & =\text { Specific kinetic energy, } \mathrm{J} \cdot \mathrm{kg}^{-1} \\
h & =\text { Specific enthalpy, } \mathrm{J} \cdot \mathrm{kg}^{-1} \\
m & =\text { Mass flow rate, } \mathrm{kg} \cdot \mathrm{s}^{-1} \\
p & =\text { Pressure, } \mathrm{kPa} \\
P_{C} & =\text { Compression power consumption, } \mathrm{kW} \\
Q_{0} & =\text { Cooling capacity, } \mathrm{kW} \\
R & =\text { Gas constant } \\
r & =\text { Gold flow fraction } \\
T & =\text { Temperature, } \mathrm{K}
\end{array}
$$

\section{Greek Symbols}

$$
\begin{array}{ll}
\Delta \mathrm{T} & =\text { Temperature difference } \\
\gamma & =\text { Specific heat ratio }
\end{array}
$$

\section{Subscripts}

$$
c \quad=\text { Cold flow }
$$$$
\text { in } \quad=\text { Inlet flow }
$$

$$
\begin{array}{ll}
h & =\text { Hot flow } \\
\text { out } & =\text { Outlet Flow } \\
s & =\text { Isentropic process }
\end{array}
$$

\section{CONFLICT OF INTEREST}

The authors confirm that this article content has no conflict of interest.

\section{ACKNOWLEDGEMENTS}

The authors are indebted to the Spanish Ministry of Education and Science (CTM2008-06468-C02-02/TECNO) and to the Spanish Ministry of the Environment and Rural and Marine Affairs (200800050084716) for their economic support to this work.

\section{REFERENCES}

[1] G.J. Ranque, "Experiences sur la detente giratoire avec simultanes d'un echappement d'air chaud et d'un enchappement d'air froid", J. Phys. Radium., vol. 4, pp. 112-114, 1933.

[2] R. Hilsch, "Die expansion von gasen im zentrifugalfeld als kälteproze", Z. Naturforschung, vol. 1, pp. 208-214, 1946.

[3] R. Kassner, and E. Knoernschild, "Friction laws and energy transfer in circular flow. Wright-Patterson air force base", Technical report F-TR-2198ND OH, 1948.

[4] D.S. Webster, "An analysis of the Hilsch vortex tube", J. ASRE Refrig. Eng., vol. 58, pp. 163-70, 1950.

[5] C.D. Fulton, "Ranque's tube", J. ASRE Refrig. Eng., vol. 58, pp. 473-9, 1950

[6] G.W. Sheper, "The vortex tube internal flow data and a heat transfer theory", Refrigeration Eng., vol. 59, pp. 985-989, 1951.

[7] J. Harnett, and Eckert. E., "Experimental study of the velocity and temperature distribution in a high velocity vortex-type flow", Trans. ASME, vol. 79, pp. 751-758, 1957.

[8] J.E. Lay, "An experimental and analytical study of vortex flow temperature separation by superposition of spiral and axial flows", Part I Trans. ASME J. Heat Transfer, vol. 81(4), pp. 202-12, 1959.

[9] J.E. Lay, "An experimental and analytical study of vortex flow temperature separation by superposition of spiral and axial flows", Part II Trans. ASME J. Heat Transfer, vol. 81(4), pp. 213-22, 1959.

[10] R.G. Deissler, and M. Perlmutter, "Analysis of the flow and energy separation in a vortex tube", Int. J. Heat Mass Transfer, vol. 1, pp. 173-91, 1960.

[11] A.J. Reynolds, "Studies of rotating fluids: I. Plane axisymmetric flow. II. The Ranque-Hilsch vortex tube". $\mathrm{PhD}$ thesis. University of London, 1961.

[12] W.S. Lewellen, "A solution for three-dimensional vortex flows with strong circulation", J. Fluid Mech., vol. 14, pp. 420-32, 1962.

[13] C.U. Lindstrom-Lang, "Gas separation in the Ranque-Hisch vortex tube", Int. J. Heat Mass Transfer, vol. 7, pp. 1195-206, 1964.

[14] M. Kurosaka, "Acoustic streaming in swirling flows", J. Fluid Mech., vol. 124, pp. 139-172, 1982.

[15] T. Amitani, Adachi T., and Kato T., "A study on temperature separation in a large vortex tube", Jpn. Soc. Mech. Eng., vol. 49, pp. 877-84, 1983.

[16] K. Stephan, S. Lin, M. Durst, F. Huang, and D. Seher, "An investigation of energy separation in a vortex tube", Int. J. Heat Mass Transfer, vol. 26, pp. 341-348. 1983.

[17] V.A. Arbuzov, Y.N. Dubnishchev, A.V. Lebedev, M.Kh Pravdina, and N.I. Yavorskii, "Observation of large-scale hydrodynamic structures in a vortex tube and the Ranque effect", Tech. Phys. Lett., vol. 23(12), pp. 938-40, 1997.

[18] A.F. Gutsol, "The ranque effect", Phys. Uspekhi, vol. 40, pp. 639658, 1997.

[19] J. Lewins, and A. Bejan, "Vortex tube optimization theory", Energy, vol. 24, pp. 931-943, 1999.

[20] B. Ahlborn, and J. Gordon, "The vortex tube as a classical thermodynamic refrigeration cycle", J. Appl. Phys., vol. 88, pp. 3645-653, 2000.

[21] V.M. Trofimov, "Physical effect in Ranque vortex tubes", JETP Lett., vol. 72(5), pp. 249-52, 2000. 
[22] S.A. Colgate, and J.R. Buchler, "Coherent Transport of Angular Momentum. The Ranque-Hilsch Tube as a Paradigm", Ann. NY Acad. Sci., vol. 898, pp.105-12, 2000.

[23] V.E. Fin'ko, "Cooling and condensation of a gas in a vortex flow", Sov. Phys.: Tech. Phys., vol. 28(9), pp.1089, 1983.

[24 ] Method of natural gas liquefaction. Russia patent No. 2202078 C2, April 2003.

[25] A. Baz, and D. Uhler, "A compressed gas powered heating system for underwater divers", Ocean Eng., vol. 13(3), pp. 273-90, 1986.

[26] A. Baz, J. Gilheany, and A. Kalvita, "Feasibility of vortex tube assisted environmental control of an underwater research habitat", Ocean Eng., vol. 15(1), pp. 34-54, 1987.

[27] T. Bruno, "Laboratory applications of the vortex tube", Can. J. Chem. Eng., vol. 64, pp. 987-8, 1987.

[28] A. Baz, R. Johston, and D. Uhler, "Dynamics of vortex tube assisted hyperbaric chambers", Ocean Eng., vol. 13(4), 387-408. 1986

[29] K.J. Riu, J.S. Kim, and I.S. Choi, "Experimental investigation on dust separation characteristics of a vortex tube", JSME Int. J. Ser. B- Fluids Thermal Eng., vol. 47(1), pp. 29-36, 2004.

[30] R.W. Martin, and K.W. Zilm, "Variable temperature system using vortex tube cooling and fiber optic temperature measurement for low temperature magic angle spinning NMR", J. Magn. Reson., vol. 168(2), pp. 202-9, 2004.

[31] R. Ebmeier, S. Whitney, S. Alugupally, M. Nelson, N. Padhye, G. Gogos, and, H.J. Viljoen, "Ranque-Hilsch vortex tube thermocycler for DNA amplification", Instrumentation Science and Technology, vol. 32(5), pp. 567-570, 2004.
[32] B. Ahlborn, J. Camire, and J.U. Keller, "Low-pressure vortex tubes", J. Phys. D: Appl. Phys., vol. 29, pp. 1469-72, 1996.

[33] J. Sarkar, S. Bhattacharyya, and M. Ram Gopal, "Optimization of a transcritical $\mathrm{CO} 2$ heat pump cycle for simultaneous cooling and heating applications", Int. J. Refrigeration, vol. 27, pp. 830-838, 2004.

[34] U. Sachin, Nimbalkar, R. M. Michael, "An experimental investigation of the optimum geometry for the cold end orifice of a vortex tube", Appl. Therm. Eng., vol. 29, pp. 509-514, 2009.

[35] A. Orhan, M. Burak, Avcı Mete, "A new vortex generator geometry for a counter-flow Ranque-Hilsch vortex tube, Appl Therm. Engi., vol. 30, pp. 2505-2511, 2010.

[36] B. Ahlborn, J. Camire, J.U. Keller, "Low-pressure vortex tubes", $J$. Phys. D: Appl. Phys., vol. 29, pp. 1469-1472, 1996.

[37] B. Boswell, and T.T. Chandratilleke, "Air-Cooling used for metal cutting", Am. J. Appl. Sci., vol. 6 (2), pp. 251-262, 2009.

[38] E.W. Lemmon, M.L. Huber, and M.O. McLinden, REFPROP, NIST Standard Reference Database 23, v.8. National Institute of Standards, Gaithersburg, MD, U.S.A., (2007).

[39] P. Promvonge, and S. Eiamsa-ard, "Experimental investigation of temperature separation in a vortex tube refrigerator with snail entrance", ASEAN J. Sci. Technol. Dev., vol. 21 (4), pp. 297-308, 2004.

[40] M.H. Saidi, and M.S. Valipour, "Experimental modeling of vortex tube refrigerator", Appl. Therm. Eng., vol. 23, pp. 1971-1980, 2003. 